\title{
A PANDEMIA DE COVID-19 E AS ALTERAÇÕES NO CONSUMO DE PANELADA EM IMPERATRIZ-MA
}

THE COVID-19 PANDEMIC AND CHANGES IN THE CONSUMPTION OF PANELADA IN IMPERATRIZ-MA

\author{
Greacy Kelly Rodrigues Azevedo \\ Greacy18@hotmail.com \\ Mestranda em Sociologia pelo PPGS/UFMA \\ ORCID: https://orcid.org/0000-0003-2408-7641
}

\section{Emilene Leite de Sousa}

emilenesousa@yahoo.com.br

Professora Adjunta da Universidade Federal do Maranhão-UFMA

Doutora em Antropologia Social pelo PPGAS/UFSC/

ORCID: https://orcid.org/0000-0003-2608-6677

\section{(c) 960}

Esta obra está licenciada sob uma licença Creative Commons Attribution-NonCommercial-ShareAlike 4.0 International License.

\section{RESUMO}

A panelada é uma preparação cozida que se constitui de gado bovino, comercializada em diversos pontos da cidade de Imperatriz-MA, por cerca de seis décadas. Nosso objetivo foi analisar o consumo de panelada na cidade de Imperatriz-MA durante a pandemia de covid-19, identificando o público consumidor, apontando os motivos para o consumo e descrevendo as alterações no consumo da panelada no contexto atual. Para isso, realizamos uma pesquisa transversal, qualitativa e quantitativa com análise documental, entrevistas com os vendedores da comida e aplicação de questionários on-line com os consumidores entre os dias 10 e 17 de junho de 2020, obtendo 208 respostas de consumidores de panelada. A pesquisa revelou que houve transformações nos modos de comer panelada, tendo o costume sofrido alterações quanto aos locais, horários e a frequência, com redução no consumo da iguaria nos espaços públicos e aumento nos espaços privados, demonstrando a relação dos respondentes com o costume, a tradição e o sentimento de pertencimento à cidade, o que permite creditar à comida o caráter de patrimônio imaterial na e da cidade de Imperatriz.

Palavras-chave: modos de comer; panelada; comida; cidade; SARS-CoV-2.

\section{ABSTRACT}

Panelada is a dish prepared with cow gut and sold in several places in the city of Imperatriz-MA, for about six decades. Our aim was to analy- 
ze its consumption in the city of Imperatriz-MA during the Covid-19 pandemic, identifying who consumes it, establishing the reasons for consumption and describing the changes in its consumption in the current context. In order to do so, we have performed a transversal, qualitative and quantitative research with documental analysis, interviewed panelada sellers, and we have also applied online questionnaires to the consumers between June 10 and 17, 2020, obtaining 208 responses. The survey revealed that there were changes in the way of consuming the food, so that the habit underwent changes in terms of places, times and frequency, with a reduction in its consumption in public spaces, and an increase of it in private spaces, demonstrating the relationship that respondents have with this custom, the tradition and the feeling of belonging to the city, which allows this dish to be credited as an intangible heritage in and from the city of Imperatriz.

Keywords: ways of eating; panelada; food; city; SARS-CoV-2.

\section{INTRODUÇÃO}

Articular os temas cidade, comida e cultura não consiste apenas em descrever o que as pessoas consomem nestes espaços, mas aprofundar como estes permitem ser acessados (COLLAÇO, 2017). A cidade é um estado de espírito, um corpo de costumes, tradições, sentimentos e atitudes, dispostos e transmitidos por tradição, ou seja, a cidade está envolta pelos hábitos e costumes de seus moradores (PARK, 1967). Entre as tradições de um local, a gastronomia ocupa um lugar de destaque, por ser um elemento importante na representação da identidade cultural de uma comunidade (WOORTMANN; CAVIGNAC, 2016).

Nesse sentido, uma comida que faz parte dos costumes adotados em algumas regiões do país, como Ceará, Norte do Tocantins, Pará e Maranhão e merecedora de realce pelo seu consumo é a panelada que, assim como a buchada, é um prato típico da culinária sertaneja, se destacando como referencial gastronômico por apresentar uma relação com a história, gerando um vínculo de identidade, retratando a cultura e a realidade local (FRANCO, 2001). Sob esse aspecto, Magnani (2003) afirma que se os costumes existem é porque possuem um sentido para aqueles que os praticam, sendo uma das tarefas da antropologia desvendá-lo.

$\mathrm{Na}$ busca por trabalhos acadêmicos sobre a panelada, embora ela seja conhecida e bastante consumida nesses locais, notamos a escassez de publicações sobre o tema, seja nas bibliotecas físicas como nos repositórios digitais das instituições, tanto em nível local como regional e nacional. Encontramos em Franklin (2008) a referência a um estudo realizado por universitários de uma instituição de ensino de Imperatriz, como um dos poucos trabalhos publicados sobre a comercialização de panelada na cidade. Esse levantamento apontou que, à época, a comer- 
cialização da comida envolvia cerca de duas mil pessoas. A partir disso, pretendemos fazer uma reflexão socioantropológica desta comida, essencialmente de rua, e das alterações sofridas no seu consumo durante a pandemia.

Em Imperatriz, cidade no Sul do Maranhão, a panelada assume destaque ainda maior, pois, dentre os costumes estabelecidos pelos citadinos, inscreve-se o costume de ir às bancas de panelada ${ }^{1}$ em diversos momentos para consumi-la, seja durante a madrugada, após as festas, ou mesmo antes e após o trabalho. Essa comida é uma preparação cozida que se constitui de tripas, bucho e nervos de gado bovino, servida geralmente acompanhada de arroz, limão, farinha e pimenta. O consumo de panelada em Imperatriz ocorre há quase seis décadas, fazendo parte do cotidiano de moradores e visitantes (BUENO, 2010; REIS, 2018).

O que observamos na cidade são inúmeros pontos de comercialização do prato, sendo um dos mais famosos o local popularmente conhecido como "Quatro Bocas" (REIS, 2018). Para termos ideia das dimensões alcançadas por esta preparação na cidade foi criado recentemente um local específico para comercialização da comida, chamado "Panelódromo Acrizio Xavier da Costa", fazendo alusão não às panelas, como alguns não nativos podem inicialmente pensar, mas especificamente referindo-se à panelada e fazendo uma homenagem ao pioneiro na venda dessa iguaria na cidade (IMPERATRIZ, 2020).

Com o surgimento da covid-19 tivemos alterações nas rotinas relacionadas ao trabalho, aos estudos, ao lazer, e, por conseguinte, aos costumes adotados pelos citadinos. Diante disso, é oportuno indagar quais possíveis alterações podem ter surgido no consumo de panelada nos espaços urbanos, sobretudo nas vias públicas onde estas bancas de panelada estão situadas. O objetivo deste artigo é analisar o consumo de panelada em Imperatriz durante esse período da pandemia, identificando: a) o perfil do público consumidor; b) as motivações do consumo; c) e as alterações nos modos de consumir panelada atualmente.

Para isso, fizemos uma pesquisa transversal, qualitativa (GOMES, 2002) e quantitativa (SEVERINO, 2016), utilizando como técnicas a pesquisa documental, aplicação de questionários on-line com os consumidores de panelada por meio do método bola de neve (PELLERANO, 2017; COSTA, 2018), e realização de entrevistas com os vendedores da iguaria para dar conta dos objetivos propostos.

Inicialmente, na pesquisa documental fizemos uma breve análise dos decretos vigentes no período estudado e dos boletins epidemiológicos emitidos pela Prefeitura de Imperatriz e pela Secretaria de Saúde do Estado do Maranhão, com a finalidade de contextualizar para o leitor a realidade da cidade durante esse momento da pandemia. Consultamos autores regionais que estudaram a relação de Imperatriz com a panelada. Em seguida, aplicamos os questionários via google forms junto aos consumidores. Paralelo a isso, realizamos entrevistas com os vendedo- 
res de panelada por meio de roteiros semiestruturados a partir de temas-chave pelo aplicativo whatsapp.

No que diz respeito à abordagem com os consumidores, em virtude das restrições impostas no momento de pandemia, a aplicação dos questionários não pôde ser realizada nos locais de consumo, optando-se assim pela distribuição de questionários on-line em redes sociais (whatsapp e instagram) entre os dias 10 e 17 de junho de 2020, por meio do método bola de neve, que consiste na replicação por quem recebia o questionário para outras pessoas de modo aleatório, evitando contemplar estritamente a rede das pesquisadoras e alcançando pessoas residentes em variados bairros da cidade, com diversos níveis de escolaridade e perfis socioeconômicos distintos.

Para Costa (2018), esse método de levantamento inicia-se pelo envio/apresentação do link de acesso ao questionário eletrônico, por meio de e-mail ou de alguma rede social virtual. Este método de encaminhamento do questionário corresponde à estratégia viral (COSTA, 2018), uma vez que, no corpo da mensagem, além da apresentação da pesquisa, há um pedido para que a mesma seja compartilhada com a rede de contatos de quem o recebeu/visualizou. Nesta pesquisa, a amostra registrou 250 respondentes, dentre estes 208 se enquadraram nos critérios estabelecidos para participar da pesquisa, sendo estes: a) residência em Imperatriz; b) consumo de panelada e c) maioridade ${ }^{3}$.

O questionário enviado continha 25 perguntas, divididas em três blocos: no primeiro buscamos identificar o perfil socioeconômico dos participantes, considerando marcadores sociais como sexo, raça, escolaridade e renda. No segundo bloco abordamos questões referentes ao consumo pelos entrevistados antes da pandemia de covid-19. No terceiro e último bloco, as questões versavam sobre o consumo de panelada durante a pandemia, para assim podermos comparar e avaliar suas alterações com relação ao local, frequência e horários. Para a análise estatística dos dados obtidos aqui, utilizamos o programa Excel 2013.

Em relação às entrevistas com os vendedores, as questões eram semiestruturadas a partir de temas como o tempo de trabalho no local e possíveis alterações na rotina laborativa e nas vendas. O fator tempo de trabalho foi considerado para compreendermos se este trabalhador estaria apto a relatar sobre as vendas antes da pandemia, para assim evitarmos um paneleiro ${ }^{4}$ que tivesse, por exemplo, se instalado no setor da panelada apenas durante a pandemia, o que inviabilizaria o comparativo através de seus relatos. Essas entrevistas também foram realizadas por meio do aplicativo de mensagens whatsapp e de falas registradas utilizando o gravador de voz do aplicativo, com as transcrições feitas de forma literal, sem retirar gírias ou vícios de linguagem, subtraindo apenas palavras repetidas em sequência.

Para analisar os achados da pesquisa utilizamos alguns dos autores da sociologia urbana, devido à relevância teórica na área, com destaque 
para Park (1967), Magnani (1996), DaMatta (1986) e Collaço (2017). Ademais, para contextualizar a realidade local utilizamos autores regionais com publicações referentes ao tema panelada, cidade e comida de rua e/ou covid-19, como Franklin (2008), Bueno (2010), Dallo, Oliveira e Lavarda (2013), Reis (2018), Silva e Lopes (2018) e Pereira (2020).

Além desta introdução, o presente artigo inicia com uma breve incursão sobre a relação de Imperatriz e a pandemia de covid-19. Posteriormente, fazemos um relato sobre a panelada em Imperatriz e apresentamos os resultados obtidos. Por fim, elaboramos as considerações gerais, retornando às categorias utilizadas e ao cumprimento dos objetivos.

\section{IMPERATRIZ DURANTE A PANDEMIA DE COVID-19}

Imperatriz é o local em que se circunscreve esta pesquisa. Localizada às margens do Rio Tocantins e distante $629,5 \mathrm{~km}$ da capital São Luís, é a segunda maior cidade do Estado do Maranhão. O município teve sua ocupação acelerada com a abertura da rodovia Belém-Brasília, após 1960, o que permitiu maior comunicação rodoviária de Imperatriz com outras cidades e estados vizinhos, por ter se tornado polo universitário, comercial e de serviços de saúde, recebendo diariamente mais de 700 mil pessoas de cidades do Maranhão, Pará e do Tocantins (FRANKLIN, 2008; SOUSA, 2009; IMPERATRIZ, 2020). Atualmente, a cidade possui cerca de 160 bairros e $1.367,90 \mathrm{~km}^{2}$ de área total. A história e o desenvolvimento da cidade deram-lhe diversos títulos, entre eles os de Princesa do Tocantins, Portal da Amazônia, Capital Brasileira da Energia e Metrópole da Integração Nacional (IMPERATRIZ, 2020).

No que concerne ao enfretamento oficial da pandemia de covid-19, o primeiro decreto emitido pelos órgãos governamentais foi o de $\mathrm{n}^{\circ} 23$, no dia 21 de março de 2020, suspendendo por 15 dias eventos com aglomeração e aulas em todas as redes de ensino e determinando o fechamento de shoppings, centros comerciais e suspensão dos atendimentos em bares e restaurantes (IMPERATRIZ, 2020).

O primeiro caso que se teve notícia na cidade circulou nas redes sociais na noite do dia 22 de março e o processo de construção de uma nova realidade social foi sendo criada nas ruas da cidade (PEREIRA, 2020). De acordo com Blanc e Conceição (2020), até o dia 14 de abril havia o registro de 14 casos na cidade e nenhum óbito, sendo Imperatriz a única entre as cidades mais afastadas da capital a apresentar um número expressivo de casos.

Mesmo com o aumento do número de casos e óbitos na cidade, no dia 18 de maio foi sancionado decreto que permitia o retorno de serviços não essenciais, desde que atendessem às normas sanitárias para prevenção da covid-19, podendo funcionar apenas pelo sistema delivery ou drive-in. Após este, observamos a emissão de inúmeros outros decretos municipais - publicados geralmente a cada 15 dias - dispondo sobre as normas de funcionamento da Administração Pública e de ati- 
vidades econômicas organizadas (IMPERATRIZ, 2020). A publicação dos decretos acontecia de forma dinâmica e impactava o cotidiano dos citadinos (PEREIRA, 2020).

Contudo, os decretos que nos interessam serão os vigentes no período de realização desta pesquisa, quando fizemos o envio dos primeiros questionários. Isto nos permite contextualizar como a cidade estava regulada no momento da pesquisa, retratando o contexto no qual os citadinos estavam envolvidos, sendo eles: os decretos de no 60 e 67, publicados nos dias 26 de maio e 15 de junho de 2020, respectivamente.

Assim, no decreto no 60 (IMPERATRIZ, 2020), já havia permissão para o funcionamento de igrejas, clubes e estabelecimentos de vendas de alimentos, com lotação de 30\% da capacidade máxima prevista. Com relação aos estabelecimentos fechados que trabalhavam com comida, as orientações eram de que fizessem a higienização adequada e aferissem a temperatura dos clientes que entrassem no local. As praças de alimentação de shoppings e galerias seguiam funcionando apenas pelo sistema delivery e drive thru. Já o decreto $\mathrm{n}^{\circ} 67$, autorizava o funcionamento das praças de alimentação de shoppings e galerias para consumo no local (IMPERATRIZ, 2020). Porém, apesar das legislações vigentes "parte da população permaneceu tentando seguir no cotidiano, seja por fatores culturais ou econômicos" (PEREIRA, 2020, p. 73).

De acordo com o boletim epidemiológico emitido pela Secretária de Saúde do Estado, Maranhão (2020), o estado apresentava até 17 de junho 64.735 casos confirmados, 779 casos ativos, 1.570 óbitos e 39.386 recuperados, sendo que, de novos casos, 188 eram na ilha de São Luís, 109 eram de Imperatriz e 1.727 distribuídos nos demais municípios do estado. Imperatriz ocupava no estado o lamentável posto de segunda cidade com maior número de casos confirmados, com 3.350, sendo a primeira a capital São Luís, com 12.276 casos.

Essas informações são descritas para facilitar o entendimento sobre a situação dos entrevistados com relação à covid-19 na cidade, no período em que responderam ao questionário. Conforme se constata, apesar das flexibilizações efetuadas nas atividades econômicas, os casos, bem como o número de óbitos, continuavam tendo um aumento considerável, assim como havia uma alta taxa de ocupação nas enfermarias e UTIs (IMPERATRIZ, 2020; MARANHÃO, 2020).

As orientações da administração diante do contexto, associadas ao receio de contaminação pela covid-19, nos remetem à ideia de medicina social elaborada por Foucault (2019), ao afirmar que no séc. XVII existia um medo urbano, um medo da cidade e angústia diante da cidade que se relacionava com as epidemias urbanas e a propagação de doenças. As disseminações dessas informações em Imperatriz impactavam na escolha de ir ou não comer panelada nos espaços públicos, como veremos com maior clareza na análise dos resultados obtidos junto aos consumidores da comida. 


\section{O CONSUMO DE PANELADA EM IMPERATRIZ}

É preciso compreender que as atividades de consumo produzem significados e representações que extrapolam o simples ato de adquirir algo, e criam subjetividades, relações simbólicas e de poder (SOUZA, 2017). Conforme mencionado, o consumo de panelada acontece de modo significativo em bancas de paneladas que estão situadas nas ruas, por isso se faz necessário definir melhor a expressão comida de rua (CONTRERAS, 2017), que é assim entendida por estar em um espaço público não edificado nem coberto, situado no entorno urbano. Logo, "comer na rua" se opõe ou se diferencia do "comer em casa" (DAMATTA, 1986) ou "comer no restaurante". De maneira geral, poderíamos dizer que se trata de uma refeição que se realiza em um espaço exterior, sem as formalidades características da mesa (DAMATA, 1984; CASCUDO, 2004).

Imperatriz registra o consumo de panelada há quase 60 anos, seja por pessoas residentes, seja por visitantes. A comida, que se constitui de tripas, do estômago e dos tendões do boi, tem duas versões sobre sua origem: uma diz que está relacionada aos ancestrais de Portugal e a outra afirma ter origem na região sertaneja (REIS, 2018). Hoje a panelada é considerada um prato típico do Nordeste, e, embora com nomes diferentes, pode ser encontrada nos estados do Ceará e do Piauí. Porém, é inegável que o prato encontrou um ponto forte de apreciação em Imperatriz, sendo consumido por todas as classes sociais (REIS, 2018).

Segundo Reis (2018), a panelada começou a se popularizar com o senhor Acrísio Xavier da Costa, chamado de Acrísio Panelada, que ficou conhecido por vender o prato pela cidade em um carrinho de mão. À época, a comida era considerada burguesa, pois somente as pessoas mais ricas da cidade encomendavam a panelada com o vendedor. Entretanto, logo passou a ser consumida por pessoas de todas as classes. Com a morte de Acrísio Panelada na década de 1980, o prato foi ganhando diversos endereços na cidade. Hoje, alguns dos principais locais onde se encontra a Panelada são: Setor Entroncamento; Camelódromo e antiga rodoviária; porém, o local mais tradicional de consumo é na Av. Bernardo Sayão, na região conhecida como Quatro Bocas, lá é onde há mais bancas de venda de panelada e onde estas ficam na posição "de costas pra rua" (REIS, 2018).

Segundo Bueno (2010), a panelada é considerada uma tradição na cidade, consumida em todos os horários desde as primeiras horas do dia até o fim da noite, inclusive durante a madrugada. Além disso, essa comida se destaca pela importância econômica na Região Tocantina (FRANKLIN, 2008) e "pode ser considerada como patrimônio cultural imaterial ${ }^{5}$ devido ao seu modo artesanal de se fazer e, também, pelo saber que é passado de geração em geração entre as famílias envolvidas na produção e comercialização do prato" (DALLO; OLIVEIRA; LAVARDA, 2013, p. 3). 
Com base nisso, em 2010, Imperatriz e as cidades vizinhas conquistaram a "Carta de Imperatriz". Nela está registrada a composição do patrimônio histórico e cultural do Sul do Maranhão no que diz respeito aos bens materiais e imateriais. O documento foi elaborado no Simpósio de Patrimônio da Universidade Estadual do Maranhão, sob a orientação da representante do Instituto do Patrimônio Histórico e Artístico Nacional (DALLO; OLIVEIRA; LAVARDA, 2013).

As bancas de panelada, improvisadas, se concentram em determinados espaços da cidade e carregam suas características próprias. Atentas a isso, nos remetemos às categorias de análise manchas e pedaços, usadas por Magnani (1996) para pensar São Paulo. Para o autor, a mancha tem sua base física permitindo a circulação de gente vinda de várias localidades, se tratando de áreas do espaço urbano dotadas de equipamentos que marcam limites e viabilizam uma prática predominante. Numa mancha de lazer os equipamentos podem ser bares e restaurantes, que constituem pontos de referência para a prática de determinadas atividades (MAGNANI, 1996). Considerando que os pontos de comercialização de panelada atendem tais critérios, eles poderiam ser contextualizados em nível local como manchas.

Outra categoria adotada por Magnani que nos interessa é a categoria denominada pedaço:

A categoria "pedaço" está ligada à rede de sociabilidade, quando o espaço assim demarcado torna-se ponto de referência para distinguir determinado grupo de frequentadores como pertencentes a uma rede de relações. O termo designa aquele espaço intermediário entre a casa e o público, onde se desenvolve uma sociabilidade básica. É nesses espaços onde se tece o cotidiano, a troca de informações e os conflitos (MAGNANI, 1996, p. 23).

Em suma, os locais fixos seriam considerados as manchas e os espaços simbólicos de interações entre pessoas que se conhecem por identificação e afinidades seriam definidos como pedaços, sendo as primeiras fixas e estes últimos não fixos. Desse modo, poderíamos considerar os locais de panelada (Entroncamento, Quatro Bocas, dentre outros) como manchas e a rede tecida de sociabilidade entre os frequentadores dos locais, como pedaços. O que se depreende disso é que embora muitos frequentem as manchas, nem todos são considerados do pedaço.

Tais categorias, que descrevem diferentes formas de uso e apropriação do espaço, constituem chaves para o entendimento e orientação na cidade, ao circunscrever pontos socialmente reconhecidos como relevantes na dinâmica urbana (MAGNANI, 1996). Assim, as formas como as bancas são distribuídas ou o comportamento que os frequentadores assumem ao comer a panelada compõem o cenário da cidade e fazem parte do espaço urbano. Esta reflexão será objeto de análise para nós, com maior profundidade, em publicação futura. 


\section{PERFIL DO CONSUMIDOR DE PANELADA}

Consideramos diversos marcadores sociais como sexo, faixa etária, raça, escolaridade e renda para nos ajudarem a entender como era formado o perfil do consumidor de panelada nesta cidade e se o consumo de fato permeava diversas classes. A Tabela 1 traz de maneira sintética os percentuais referentes a essas respostas.

Tabela 1 - Perfil dos consumidores de panelada

\begin{tabular}{|c|c|c|c|c|c|}
\hline $\begin{array}{l}\text { Tempo na ci- } \\
\text { dade (anos) }\end{array}$ & Sexo & $\begin{array}{l}\text { Faixa } \\
\text { etária }\end{array}$ & Raça & Escolaridade & Renda (R\$) \\
\hline $\begin{array}{l}\text { Nativo } \\
34 \% \\
>16 \\
42 \% \\
11 \text { a } 15 \\
7 \% \\
6 \text { a } 10 \\
6 \% \\
1 \text { a } 5 \\
11 \%\end{array}$ & $\begin{array}{l}\text { Fem. } \\
51 \% \\
\text { Masc. } \\
49 \%\end{array}$ & $\begin{array}{l}\text { Jovens } \\
27 \% \\
\text { Adultos } \\
72 \% \\
\text { Idosos } \\
1 \%\end{array}$ & $\begin{array}{l}\text { Branca } \\
35 \% \\
\text { Parda- } \\
51 \% \\
\text { Negra } \\
13 \% \\
\text { Indígena } \\
0 \% \\
\text { Amarela } \\
0 \% \\
\text { Outros } \\
1 \%\end{array}$ & $\begin{array}{l}\text { Fundamental } \\
1 \% \\
\text { Médio } \\
13 \% \\
\text { Superior } \\
38 \% \\
\text { Especialização } \\
33 \% \\
\text { Mestrado } \\
10 \% \\
\text { Doutorado } \\
5 \%\end{array}$ & $\begin{array}{l}\text { Sem renda } \\
6 \% \\
\text { Menos de } \\
1.045,00 \\
9 \% \\
1.046,00 \text { a } \\
2.000,00 \\
17 \% \\
2.001,00 \text { a } \\
4.000,00 \\
26 \% \\
4.001,00 \text { a } \\
6.000,00 \\
13 \% \\
6.001,00 \text { a } \\
8.000,00 \\
12 \% \\
8.001,00 \text { a } \\
10.000,00 \\
7 \% \\
\text { Mais de } \\
10.000,00 \\
10 \%\end{array}$ \\
\hline
\end{tabular}

Fonte: Pesquisa de campo

Em suma, os dados revelam que $76 \%$ dos respondentes nasceram na cidade ou residem há mais de 16 anos, demonstrando dessa forma que o fator tempo de moradia se reflete no consumo de panelada. Isso posto, recordamos o que asseverou Montanari (2008), ao afirmar que a comida não é boa ou ruim por si só, mas que alguém nos ensinou a reconhecê-la como tal. Nesse sentido, dada a relação histórica da panelada com a cidade, a partir da sociologia de Elias (1994), atrelamos o seu consumo não exclusivamente ao gosto pessoal, mas à configuração social em que os indivíduos estão envolvidos desde a infância, seja observando pessoas da sua rede de contatos preparando a panelada, seja consumindo-a ou simplesmente escutando pessoas próximas se remetendo à sua existência.

Embora em percentual notadamente menor, também verificamos pessoas com menos tempo de moradia na cidade se configurando como consumidores da panelada, o que aqui é lido sob a ótica de Bourdieu 
(2008), para quem, sob pena de se sentirem deslocados, os que penetram em um espaço devem cumprir as condições que ele exige de seus ocupantes. Para Cascudo (2004), isso se refere à ligação dos indivíduos à localidade da comida, que permite integrar as pessoas por intermédio do ato de comer, que pode funcionar como estratégia de adaptação dos migrantes na chegada a um novo local. Assim, pensamos a partir de Elias (1994) e suas categorias de estabelecidos e outsiders, em que o ato de comer panelada pode funcionar como uma estratégia de socialização e pertencimento junto aos moradores de Imperatriz. Logo, o morador da cidade que não aprecia a panelada pode ser compreendido como um outsider, sendo a decisão por não comer panelada um indicativo de não identificação e não pertencimento à cidade.

O marcador sexo dos consumidores mostra uma leve preponderância de mulheres, um resultado interessante a ser analisado, tendo em vista que DaMatta (1986) inferiu que, num sentido culturalmente difundido, falava-se sempre que quem come é o homem, enquanto a mulher cozinha e dá os alimentos e a comida. Aqui observamos que, dada as transformações sociais ocorridas ao longo do tempo, com a inserção no mercado de trabalho e demais conquistas, a mulher passa a ser não apenas a preparadora, mas a assumir o posto de consumidora, incluindo o consumo alimentar realizado nas ruas. Com relação à faixa etária, a maior parcela compreende entrevistados com idades entre 30 e 59 anos, critério que serve para observarmos quem compunha a maior parte do nosso público: neste caso, adultos responsáveis pela escolha sobre o que, quando e onde consumir.

Ao longo da pesquisa percebemos diversos autores locais (REIS, 2018; BUENO, 2010) se referirem à panelada como um prato consumido por todas as classes e raças, e para verificarmos se estas afirmações também contemplavam o enquadramento social dos nossos respondentes incluímos esses marcadores. $\mathrm{O}$ aspecto raça foi incluído para compor o perfil socioeconômico dos entrevistados e responder aos objetivos elencados para a pesquisa, que se propunha a identificar o perfil do público consumidor, tendo aqui a maioria dos entrevistados se autodeclarado pardo, o que corrobora a afirmação do IBGE (2019), que na Pesquisa Nacional por Amostra de Domicílios (PNAD) teve 46,8\% dos entrevistados se declarando como pardos. A pesquisa mostrou no quesito escolaridade a prevalência de pessoas com ensino superior completo ou em curso. Sobre a renda, o maior percentual situou-se entre 1 e 4 salários mínimos, revelando que, embora seja uma comida encontrada a preços populares, a panelada é consumida por pessoas de diversos perfis socioeconômicos, conforme veremos adiante.

\section{LOCAL DE MORADIA DOS CONSUMIDORES}

Para Mello e Simões (2013), uma dimensão importante da experiência urbana de um citadino se revela ao considerarmos o seu endereço, 
pois nos permite facultar ao outro o acesso a um lugar que compõe parte da nossa própria identidade. Logo, acredita-se que o lugar de residência na cidade possa interferir nas escolhas cotidianas do indivíduo, inclusive nas escolhas alimentares. Com relação ao local de moradia dos entrevistados, conforme a Tabela 2, foram citados 54 bairros, que se situam de norte a sul da cidade.

Tabela 2: Bairros de residência dos consumidores entrevistados

\begin{tabular}{|l|c|c|}
\hline Bairro & Quantidade & $\mathbf{\%}$ \\
\hline Nova Imperatriz & 35 & 17 \\
\hline Bacuri & 23 & 11 \\
\hline Centro & 21 & 10 \\
\hline Vila Lobão & 11 & 5 \\
\hline Parque do Buriti & 8 & 4 \\
\hline Santa Rita & 8 & 4 \\
\hline Demais 48 bairros & 102 & 49 \\
\hline Total & 208 & 100 \\
\hline & & \\
\hline
\end{tabular}

Fonte: Pesquisa de campo

Interessante perceber nesta pesquisa que o local de residência não foi condicionante para a decisão sobre o consumo ou não da panelada, visto que vários sujeitos se predispunham a se deslocar para lugares distantes de sua residência para saborear o prato. Assim, os bairros de residência dos interlocutores da pesquisa eram tanto próximos quanto distantes geograficamente dos pontos de vendas mencionados, o que demonstra que o consumo da panelada se dá não apenas pelos comensais das regiões circunvizinhas, mas por moradores de várias partes da cidade.

Outro aspecto que verificamos são que os bairros mais citados na pesquisa compõem um público que contempla diversas classes sociais no mesmo bairro, isso visto pelo exemplo percebido entre os residentes do bairro Nova Imperatriz, onde ao analisarmos os dados observamos pessoas ganhando desde menos de um salário mínimo a mais de 10 mil reais e de diversos níveis de escolaridade, desde os considerados mais baixos aos mais elevados. O que não significa que não haja outros modos de hierarquização da estrutura social internas ao próprio bairro. Como revela Bourdieu (2008), todo espaço em uma sociedade hierarquizada apresenta suas hierarquias e exprime as distâncias sociais. Nesses bairros as distâncias sociais podem ser demarcadas pelos diversos tipos de casa ou pelas desiguais condições de vida. Ou seja, ao invés das hierarquizações serem entre os diversos bairros, o que se percebe é uma hierarquização interna aos mesmos.

Curioso compreender como um elemento que compõe a dieta alimentar de um povo é revelador da estrutura ou da organização social da cidade, como assevera DaMatta (1986). O autor demonstra que o hábito 
de misturar os elementos culinários no prato revela a formação do povo brasileiro, constituída por uma mistura de raças. Ao analisarmos os dados atentamos que a não hierarquização de classes sociais por bairros na cidade se manifesta no consumo da própria panelada, pois não há fronteiras geográficas dentro dos bairros para as classes, assim como não há fronteiras dentro da cidade para o consumo da panelada.

\section{ALTERAÇÕES NO CONSUMO DE PANELADA NA PANDEMIA}

Compreendemos que analisar os modos de comer de um povo é uma das formas de penetrar na estrutura social e conhecer suas preferências (WOORTMAN; CAVIGNAC, 2016), pois, através do entendimento do que um determinado povo come e quando, pode-se entender o seu modo de ser e de pensar (CASCUDO, 2014). Conforme Sousa (2017), “é possível fazer interessantes leituras sobre a vida social de um povo por meio do cardápio que ele nos apresenta. A alimentação revela a estrutura da vida cotidiana do seu núcleo mais íntimo e compartilhado" (SOUSA, 2017, p. 358).

Os motivos para o consumo da panelada no espaço urbano variam por uma série de razões que perpassam questões ligadas a segurança, higiene, sabor, tradição, praticidade, entre outros. Por isso, nos dedicaremos à análise das mudanças - em razão da pandemia de covid-19 - nos modos de comer panelada, que expressaram alterações substanciais quanto aos locais, frequências e horários de consumo, como veremos adiante.

\section{ALTERAÇÕES QUANTO AO LOCAL DE CONSUMO E SUAS MOTIVAÇÕES}

Em qualquer cidade brasileira, há uma divisão clara entre dois espaços sociais fundamentais que dividem a vida social: a casa e a rua (DAMATTA, 1986). Para compreendermos acerca do local em que estavam fazendo o consumo de panelada durante a pandemia, se em casa ou na rua, listamos as respostas obtidas no Gráfico 1:

Gráfico 1- Alterações no local de consumo de panelada na pandemia

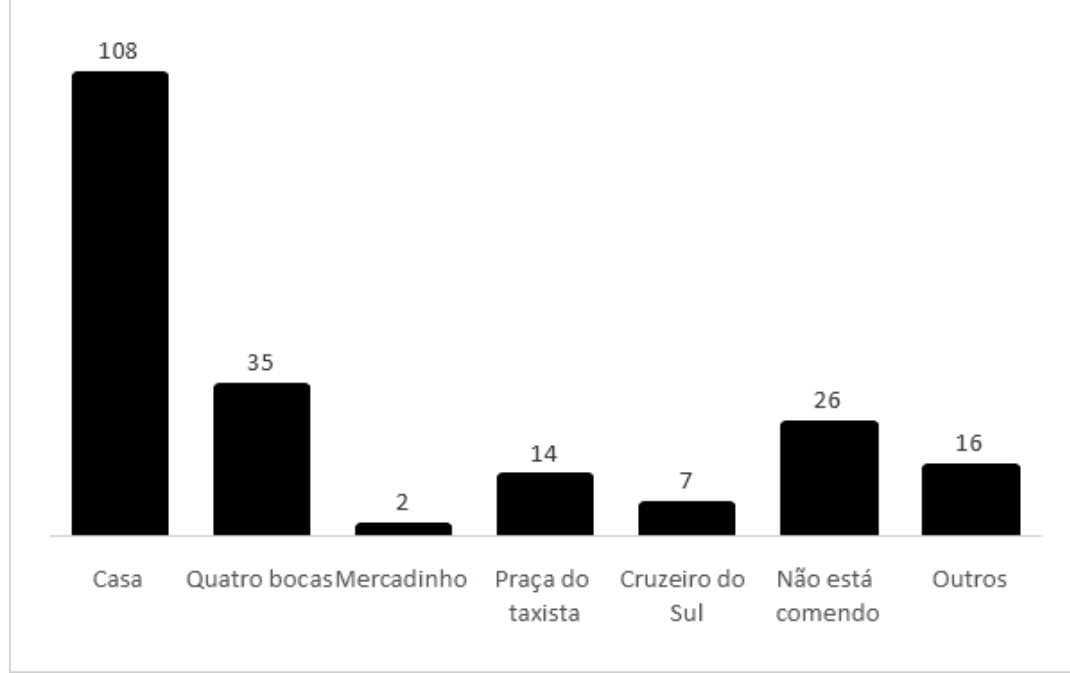

Fonte: Pesquisa de campo 
Como observado no Gráfico 1, grande parte dos entrevistados passou a comer panelada apenas em casa durante a pandemia, enquanto uma pequena parcela relatou não está comendo, fazendo menções a evitar saídas às ruas e possíveis aglomerações pelo medo da contaminação. Nesse sentido, uma reflexão de Collaço (2017) expõe uma relação que nos ajuda a entender a atualidade entre a ética e o poder no consumir, pois uma escolha alimentar individual a favor da coletividade constitui também uma forma de moralidade e de fazer política e pode revelar, além de escolhas pessoais, um posicionamento da rede coletiva na qual o indivíduo está inserido. Entretanto, verificamos que um percentual considerável de respondentes optou por continuar a sair para comer a panelada nos locais considerados públicos da cidade, relacionando a sua escolha ao sabor e tradição da comida comercializada na rua. Para Park (1967), isso surge em resposta a influências pessoais e ao sentimento público.

Além das alterações com relação aos locais, contemplamos as questões referentes a níveis de renda, seguindo a ideia adotada por Silva (2016) ao analisar o botequim, quando o autor observou em especial a variável classe social dos consumidores. Para ele, os motivos e sentidos que levavam os consumidores a procurar os locais são diferentes. Buscando perceber se havia diferenças entre as escolhas por parte de pessoas dos diferentes níveis econômicos, apresentamos, na Tabela 3, os resultados encontrados em relação a renda e mudanças quanto ao local de consumo durante a pandemia.

Tabela 3 - Relação da renda e mudanças quanto ao local de consumo durante a pandemia

\begin{tabular}{|l|c|c|c|c|c|c|}
\hline \multicolumn{1}{|c|}{ Renda } & $\begin{array}{c}\text { Não } \\
\text { Consumo }\end{array}$ & Casa & $\mathbf{4}$ Bocas & $\begin{array}{c}\text { Praça do } \\
\text { Taxista }\end{array}$ & $\begin{array}{c}\text { Cruzeiro } \\
\text { do Sul }\end{array}$ & Outros \\
\hline Sem renda & $-50,00 \%$ & - & $-57,14 \%$ & - & $-100,00 \%$ & $100,00 \%$ \\
\hline Menos de $1.045,00$ & $0,00 \%$ & $1200,00 \%$ & $-81,82 \%$ & $-100,00 \%$ & $-100,00 \%$ & $100,00 \%$ \\
\hline $1.045,00$ a $2.000,00$ & $-50,00 \%$ & $850,00 \%$ & $-30,77 \%$ & $-33,33 \%$ & $-83,33 \%$ & $-66,67 \%$ \\
\hline $2.001,00$ a $4.000,00$ & $20,00 \%$ & $2600,00 \%$ & $-70,83 \%$ & $66,67 \%$ & $-77,78 \%$ & $-85,71 \%$ \\
\hline $4.001,00$ a $6.000,00$ & $-20,00 \%$ & - & $-45,45 \%$ & $0,00 \%$ & $-60,00 \%$ & $-80,00 \%$ \\
\hline $6.001,00$ a $8.000,00$ & $-25,00 \%$ & $1400,00 \%$ & $-64,29 \%$ & $0,00 \%$ & $-100,00 \%$ & $-66,67 \%$ \\
\hline $8.001,00$ a $10.000,00$ & $0,00 \%$ & $800,00 \%$ & $-85,71 \%$ & $0,00 \%$ & $-100,00 \%$ & $0,00 \%$ \\
\hline Mais de $10.000,00$ & $-20,00 \%$ & - & $-42,86 \%$ & - & $-33,33 \%$ & - \\
\hline Total & $-16,67 \%$ & $1700,00 \%$ & $-60,64 \%$ & $9,09 \%$ & $-77,42 \%$ & $-62,50 \%$ \\
\hline
\end{tabular}

Fonte: Pesquisa de campo

Percebe-se que em todos os níveis de renda prevaleceu entre os respondentes a redução do consumo na rua e o aumento do consumo em casa, seja preparando-a, pedindo por delivery ou passando no local para buscar e comer em casa. Esses dados ratificam que os consumidores não abandonaram o consumo do prato, mas o ressignificaram para o ambiente doméstico. Acerca disso, Souza (2017, p. 48) afirma que a sociedade atribui significados múltiplos às escolhas que levam ao consumo, os quais podem ser positivos ou negativos, a depender do contexto. Em determi- 
nados momentos, o consumo de algo pode ser percebido como alienação e ação individualista, em outros, é visto como experiência e realização. Assim, o consumo de comidas se relaciona com o contexto no qual o indivíduo está inserido, não podendo ser analisado desvinculado dessa realidade.

De acordo com a tabela observamos queda entre $60 \%$ a $77 \%$ da comercialização da panelada em alguns lugares públicos de consumo. Essa informação também foi corroborada por uma entrevista concedida pelos paneleiros a um jornal local, cujos relatos afirmam que os locais de comercialização não fecharam em nenhum momento durante a pandemia, todavia apresentaram uma queda nas vendas da comida em $70 \%$ durante esse período. Com a flexibilização dos decretos, relatou uma das vendedoras: "aos poucos o movimento está voltando ao normal. Dias atrás não se via um 'cristão' por aqui” (CARVALHO, 2020).

Os dados sobre a diminuição das vendas nos locais foram percebidos nas entrevistas que realizamos com os vendedores. Na primeira entrevista, realizada com uma vendedora situada nas Quatro Bocas, obtivemos o seguinte relato:

Assim né fia, mudou um pouco, tá mais fraco, tem gente que não tá indo trabalhar, tá fraco as vendas né, porque não tem festa, aí fica fraco mesmo, mas sempre a gente vende, é porque lá é da minha irmã, eu trabalho lá 2 noites na semana só, trabalho lá acho que já tem uns 16 anos, sempre a gente vende, dá de sair, ficou mais fraco mesmo porque antigamente era melhor porque o povo saia, tinha as festas, tinha tudo, agora não tá tendo festa nem nada, mas dar de vender um pouco ainda (VENDEDORA $A^{6}$ ).

Essa fala confirma a redução nas vendas e no consumo nas vias públicas, sendo atribuído por ela principalmente à ausência de festas que marcavam o cotidiano da cidade antes da pandemia.

Além das afirmações da vendedora acima, realizamos outra entrevista com um paneleiro do Setor Entroncamento, as considerações foram:

É o seguinte, com relação a esse isolamento social o governo faz uma campanha pesada dizendo, fique em casa, fique em casa, sendo que ele não faz a parte dele, a conta de água, de energia, os boletos estão todos chegando, como é que a gente fica em casa desse jeito? Não tem condições. A nossa sorte é que farmácia e esses ramos alimentícios podem continuar abertos, é lógico que dá uma queda, mas não na proporção das outras profissões. Minha família trabalha a mais de 40 anos no ponto, hoje sou a terceira geração! (VENDEDOR B).

Acerca disso, algo que chama a atenção na fala do vendedor B é a necessidade de continuar trabalhando mesmo em condições adversas. Sobre isso, Sousa Santos (2020, p. 18) afirma que "a indicação por parte da OMS para trabalhar em casa e em autoisolamento é impraticável, porque obriga os trabalhadores a escolher entre ganhar o pão diário ou ficar em casa e passar fome". 
Além disso, através destes relatos verificamos que o ofício de ser paneleiro se configura como familiar e intergeracional, na medida em que envolve vários membros da mesma família, garantindo a circulação do conhecimento sobre os modos de fazer entre as gerações. Esta informação é consolidada pela pesquisa realizada por Dallo, Oliveira e Lavarda (2013), em que afirmaram que o saber-fazer panelada é transmitido através das gerações entre os familiares.

Questionamos aos consumidores que responderam preferir comer panelada em casa sobre quais motivos norteavam essa escolha, seguem os dados no Gráfico 2.

Gráfico 2 - Motivos para preferir comer em casa

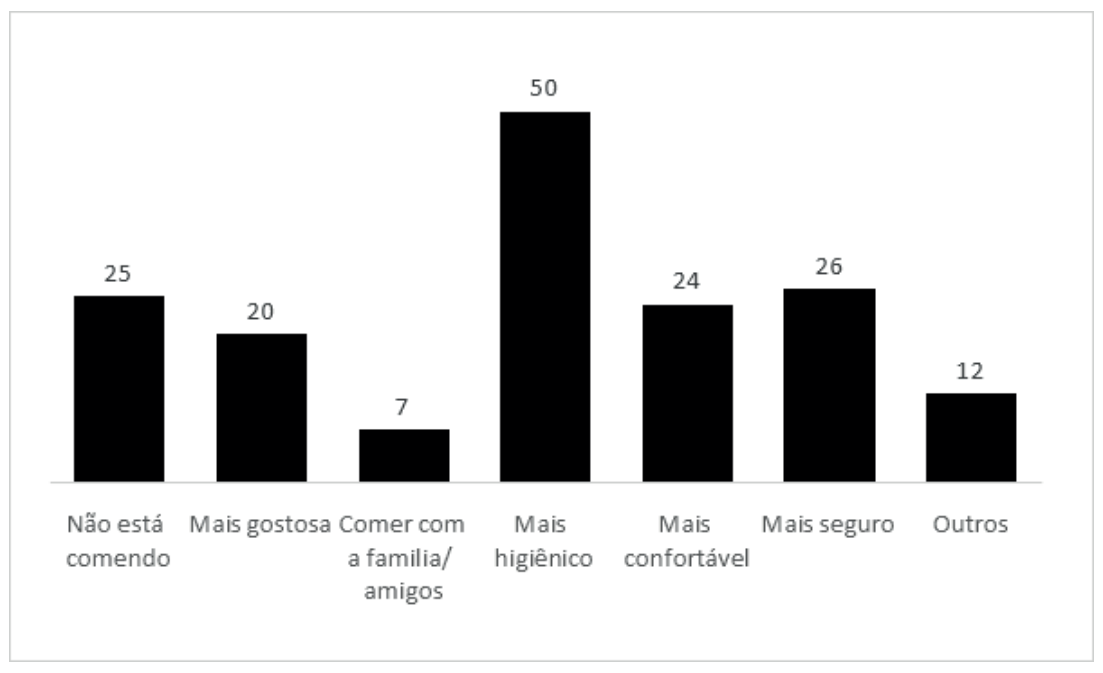

Fonte: Pesquisa de campo

Observamos que a maioria optou por comer em casa por considerar mais higiênico, seguido da opção mais seguro, sendo tal fato apontado como forma de evitar aglomerações e em razão do receio de contaminação por covid-19. Aparecem empatadas as respostas "não está comendo" e "ser mais confortável". Segundo Douglas (1975), as formas de se alimentar constituem uma linguagem, aquilo que escolhemos ou evitamos comer e os modos de fazê-lo expressam dimensões culturais e relações sociais.

Aos consumidores que preferiam fazer o consumo em casa, questionamos se sentiam falta de consumir panelada em espaços públicos e por quais motivos. 
Gráfico 3 - Do que sente falta de comer na rua

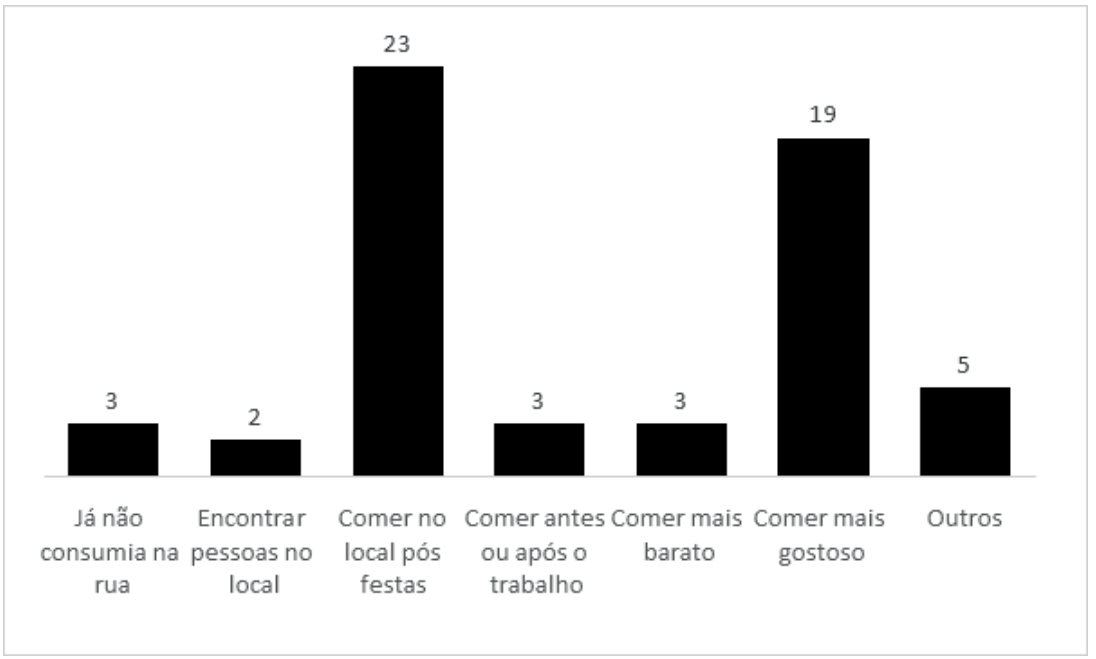

Fonte: Pesquisa de campo

A maior parte relatou, respectivamente: a) sentir mais falta do costume de sair das festas e passar no local para comer; b) a comida ser mais saborosa que aquela feita em casa. Sobre o primeiro aspecto, Silva e Lopes (2018) encontraram um resultado similar em suas pesquisas no norte do Tocantins, onde constataram que um dos motivos que fazia reduzir o consumo de panelada eram períodos sem festas na cidade. O mesmo aconteceu em Imperatriz, com as restrições impostas pela pandemia quanto à realização de festas, havendo redução do consumo de panelada nas ruas. No que diz respeito ao aspecto sabor, remetemos à Souza (2017) que, ao analisar o consumo, mencionou as cozinhas regionais, afirmando que as comidas são preparadas a partir de uma determinada técnica de cozimento e apresentadas sob uma forma específica. Essa ideia nos auxilia a entender o porquê de os respondentes considerarem a comida da rua mais gostosa, justamente pelo modo de preparo utilizado pelos paneleiros.

Sobre os motivos por optarem pelo consumo em espaços públicos, segue no Gráfico 4 as respostas encontradas.

Gráfico 4 - Motivos para continuar preferindo comer na rua

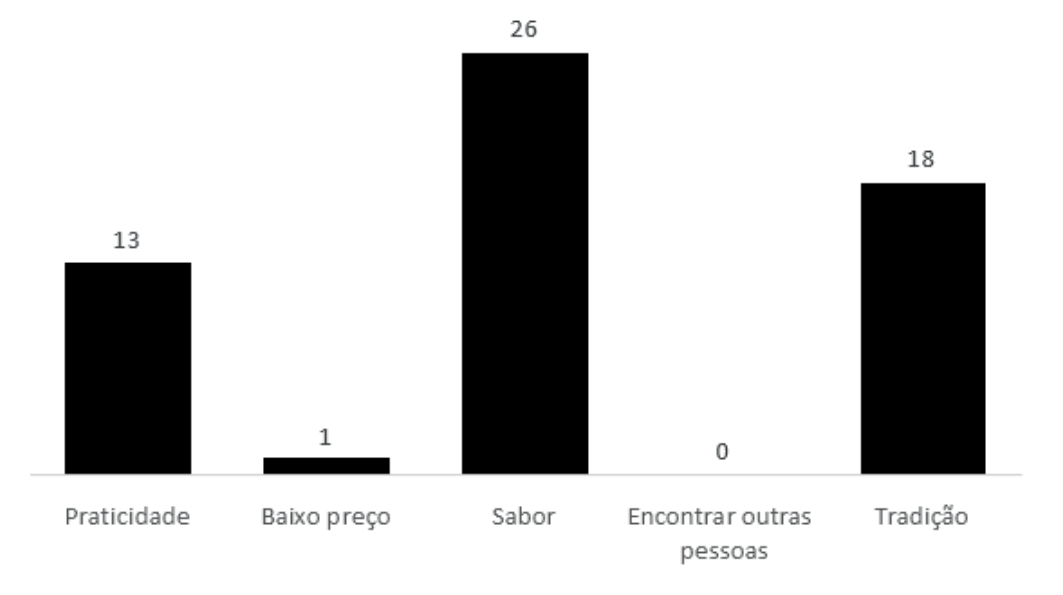

Fonte: Pesquisa de campo 
Grande parte dos que preferiam comer a panelada na rua o faziam por achar mais gostosa do que a preparada em casa. O que é apoiado pelo estudo de Dallo, Oliveira e Lavarda (2013), para quem a fama da comida na cidade está associada ao modo artesanal e particular dos paneleiros fazerem a panelada. O segundo motivo mais apontado foi por considerar comer panelada na rua como parte da tradição da cidade. Com relação a isso, para Silva e Lopes (2018) os sentidos conferidos aos pratos típicos são referentes à cultura, tradição e identidade, pois o compartilhamento das comidas reforça o sentimento de pertencimento a um lugar e às suas tradições. $O$ terceiro motivo elencado pelos sujeitos da pesquisa foi a praticidade; segundo Contreras (2017), comer na rua oferece às pessoas rapidez, simplicidade e praticidade; e, justamente, como referido pelos nossos interlocutores, o motivo para não realizar o preparo da refeição em casa era devido ao trabalho e às técnicas envolvidas no preparo.

\section{ALTERAÇÕES QUANTO À FREQUÊNCIA DE CONSUMO DA PANELADA}

Outra mudança apontada pelos entrevistados referiu-se à frequência do consumo de panelada. Listamos na Tabela 4 os resultados encontrados.

Tabela 4 - Mudanças no consumo de panelada na rua quanto à frequência

\begin{tabular}{|l|c|c|}
\hline \multicolumn{1}{|c|}{ Periodicidade } & Antes da pandemia & Durante a pandemia \\
\hline Diário & $2 \%$ & $1 \%$ \\
\hline Semanal & $13 \%$ & $5 \%$ \\
\hline Quinzenal & $15 \%$ & $7 \%$ \\
\hline Mensal & $30 \%$ & $15 \%$ \\
\hline Trimestral & $14 \%$ & - \\
\hline Semestral & $12 \%$ & - \\
\hline Outros & $14 \%$ & $26 \%$ \\
\hline Não está comendo na rua & - & $46 \%$ \\
\hline & & \\
\hline
\end{tabular}

Fonte: Pesquisa de campo

Observou-se que a maior alteração foi quanto ao não consumo da panelada nos espaços públicos da cidade, apresentando redução nas demais frequências de consumo na rua pelos consumidores. Isto é, mesmo quem optou por continuar comendo na rua, reduziu a frequência. Segundo Pellerano (2017), as práticas em torno da comida, contemplando a compra, o preparo e o comer fora, podem mudar ao longo do tempo, ou em condições adversas. Resultados esses que também vimos ao analisarmos as reduções na periodicidade no consumo de panelada na rua durante o período de isolamento social na cidade de Imperatriz. 


\section{ALTERAÇÕES REFERENTES AOS HORÁRIOS DE CONSUMO}

Quando questionados sobre as mudanças referentes aos horários de consumo, antes e durante a pandemia, as informações estão listadas na Tabela 5:

Tabela 5 - Mudanças no consumo de panelada quanto ao horário

\begin{tabular}{|l|c|c|}
\hline \multicolumn{1}{|c|}{ Horário da refeição } & Antes da pandemia & Durante a pandemia \\
\hline Café da manhã & $3 \%$ & $2 \%$ \\
\hline Almoço & $25 \%$ & $51 \%$ \\
\hline Jantar & $32 \%$ & $20 \%$ \\
\hline Após festas ou show & $31 \%$ & $4 \%$ \\
\hline Não estou comendo & - & $21 \%$ \\
\hline Outros & $9 \%$ & $2 \%$ \\
\hline & \multicolumn{2}{|}{} \\
\hline
\end{tabular}

Fonte: Pesquisa de campo

Os dados demonstram que quanto aos horários para degustar a panelada houve o aumento do consumo no almoço e diminuição no jantar e após as festividades na madrugada. Logo, o consumo de panelada, que ocorria em diversos horários, mas notadamente nas noites e nas madrugadas pós festividades, com a proibição da realização das festas, sofreu modificação. De acordo com Menasche, Alvarez e Collaço (2012), o horário das refeições são instâncias codificadas que podem afirmar a identidade alimentar e selar o pertencimento alimentar referente a um determinado território. As alterações impostas pelo cenário pandêmico impactam a rotina dos citadinos e dos vendedores e reconfiguram, ainda que momentaneamente, as escolhas alimentares.

\section{CONSIDERAÇÕES FINAIS}

Tendo em vista o objetivo proposto, qual seja, analisar as alterações no consumo da panelada em Imperatriz durante a pandemia de Covid-19, verificamos a redução da ingestão da panelada nos espaços públicos para o aumento nos espaços privados, demonstrando que mesmo durante a pandemia - dado o valor simbólico e cultural da panelada - o costume continuou apresentando destaque, tendo sido reinventado, mas não descartado.

Observamos que com o surgimento da pandemia, mesmo entre os que continuaram a comer panelada na rua, houve a redução do número de vezes que se comia no local. Além desta, outra mudança foi quanto ao horário de consumo do prato, tendo aumentado a busca pelo prato no almoço e diminuído no jantar e após as festividades na madrugada.

Com relação aos demais objetivos levantados, encontramos um perfil variado de consumidores de panelada, em sua maioria adultos, com leve predominância de mulheres e níveis de renda e escolaridade diversificados. Sobre os que optaram por comer em casa, os motivos 
relatados foram higiene, segurança, conforto e companhia familiar. Dos que escolheram comer nas bancas de rua, os motivos apontados foram: sabor, tradição e praticidade. Em suma, o que se percebe é que independente do local de residência, sexo, classe econômica e faixa etária, mesmo durante a pandemia persistiu o consumo de panelada, creditando à comida o caráter de patrimônio imaterial na e da cidade.

O que se torna relevante, além da possibilidade de comparar alterações sobre os modos de comer, especialmente em um período pandêmico, é permitir que uma preparação conhecida apenas em nível regional se torne conhecida por pesquisadores de outras localidades. Portanto, não pretendemos esgotar as questões sobre a panelada, mas instigar entre os cientistas sociais a diversidade de análises possíveis sobre ela, que possam contribuir com as lacunas ainda existentes nessa esfera de conhecimento. Esta pesquisa abre oportunidades de estudo para que questões aqui levantadas sejam aprofundadas.

\section{NOTAS}

1. São designadas bancas os locais improvisados de vendas de comida de rua, onde os utensílios são expostos em mesas de madeira, os consumidores ficam sentados em bancos de madeira, posicionados de frente para as bancas nas calçadas e, automaticamente, de costas para a rua.

2. Denominação popular utilizada para se referir a um setor comercial da cidade onde nas calçadas estão dispostas as bancas de comercialização de panelada. 3. Essa exigência refere-se ao recorte dos sujeitos da pesquisa e à importância do aceite de participação por meio do Termo de Consentimento Livre e Esclarecido, inserido no início do questionário, onde apenas após concordar com os termos, o respondente ficava habilitado para as demais questões. O termo explicava sobre a participação voluntária e a garantia de confidencialidade, de acordo com a Resolução CNS no 510/2016.

4. 4. O termo paneleiro se refere à autodenominação dos produtores e vendedores de panelada na cidade, cuja nomenclatura está contemplada no nome da Associação das Paneleiras de Imperatriz.

5. Para o Instituto do Patrimônio Histórico e Artístico Nacional - IPHAN (2021) os bens culturais de natureza imaterial dizem respeito àquelas práticas e domínios da vida social que se manifestam em saberes, ofícios e modos de fazer, sendo transmitido de geração a geração.

6. Utilizamos as nomenclaturas Vendedor A e Vendedor B como forma de preservar a confidencialidade dos vendedores de acordo com a resolução $\mathrm{n}^{\circ}$ 510/2016 (BRASIL, 2016).

\section{REFERÊNCIAS}

BLANC, Manuela; CONCEIÇÃO, Wellington da Silva. Cidades, seus fluxos e o espraiamento viral: as prospecções possíveis em uma análise da incidência da covid-19 em TO, MA, ES e RJ. Dilemas: revista de estudos de conflito e controle social - reflexões na pandemia, p. 1-27, 2020. Disponível em: <https://www.reflexpandemia .org/texto-15>. Acesso em: 20 maio 2020. 
BOURDIEU, Pierre. Efeitos de lugar. In: BOURDIEU, Pierre (coord.). A miséria do mundo. Petrópolis: Vozes, 2008.

BRASIL. Ministério da Saúde. Conselho Nacional de Saúde. Resolução $n^{\circ}$ 510, de 07 de abril de 2016. Disponível em: <http://conselho.saude.gov.br/resolucoes/2016 /Reso510.pdf>. Acesso em: 02 maio 2021.

BUENO, Thaisa. Panelada: um dos pratos típicos da cidade de Imperatriz. Imperatriz Notícias, 2010. Disponível em: <https://imperatriznoticias.ufma.br/geral/panelada-um-dos-pratos-tipico-da-cidade-de-imperatriz/>. Acesso em: 21 jun. 2020.

CARVALHO, David. Tradicional panelada de Imperatriz funciona normalmente. Imperatriz On-line, 8 jun. 2020. Disponível em: <https:// imperatriz.online/2020/06/08/tradicional-panelada-de-imperatriz-funciona-normalmente/>. Acesso em: 11 jun. 2020.

CASCUDO, Luiz da Câmara. Antologia da alimentação no Brasil. São Paulo: Global, 2004.

COLLAÇO, Janine Helfst Leicht. Espaço urbano e consumo alimentar: trajetórias locais e diferença em três cidades brasileiras. In: COLLAÇO, Janine Helfst Leicht; BARBOSA, Filipe Augusto Couto; ROIM, Talita Prado Barbosa (orgs.). Cidades e consumo alimentar: dinâmicas socioculturais do comer no espaço urbano. Goiânia: Imprensa Universitária, 2017. v. 1.

CONTRERAS, Jesus. Comer na Rua. In: COLLAÇO, Janine Helfst Leicht; BARBOSA, Filipe Augusto Couto; ROIM, Talita Prado Barbosa (orgs.). Cidades e consumo alimentar: dinâmicas socioculturais do comer no espaço urbano. Goiânia: Imprensa Universitária, 2017. v. 1.

COSTA, Bárbara Regina Lopes. Bola de neve virtual: o uso das redes sociais virtuais no processo de coleta de dados de uma pesquisa científica. Revista Interdisciplinar de Gestão Social, v. 7, n. 1, p. 15-37, jan./abr. 2018.

DA MATTA, Roberto. O que faz o brasil, Brasil? Rio de Janeiro: Rocco, 1986.

DALLO, Elicléia Clarícia; OLIVEIRA, Fernando Ralfer de Jesus; LAVARDA Marcus Túlio Borowiski. De Costas pra Rua: vídeo documentário sobre a panelada em Imperatriz (MA). Sociedade Brasileira de Estudos Interdisciplinares da Comunicação, 2013. Disponível em: <https://pt.scribd.com/document/403097292/De-Costas-Pra-Rua-Video-Documentario-Sobre-a-Panelada-Em-Imperatriz $>$. Acesso em: 28 maio 2020.

DOUGLAS, Mary. Implicit meanings: essays in anthropology. Londres: Routledge \& Paul, 1975.

ELIAS, Norbert. A sociedade dos indivíduos. Rio de Janeiro: Jorge Zahar, 1994.

FOUCAULT, Michel. Microfísica del poder. Buenos Aires: Siglo Veinteuno, 2019. 
FRANKLIN, Adalberto. Apontamentos e fontes para a história econômica de Imperatriz. Imperatriz: Ética, 2008.

FRANCO, Areovaldo. De caçador a gourmet uma história da gastronomia. 2. ed. São Paulo: SENAC, 2001.

GOMES, Romeu. A análise de dados em pesquisa qualitativa. In: MINAYO, Maria Cecília de Souza (org.). Pesquisa social: teoria, método e criatividade. 21 ed. Petrópolis: Vozes, 2002.

IMPERATRIZ. Prefeitura Municipal de Imperatriz-MA. A cidade. s.d. Disponível em: <http://www.imperatriz.ma.gov.br/portal/imperatriz/a-cidade.html >. Acesso em: 10 set. 2020.

IMPERATRIZ. Decreto n. ${ }^{\circ}$ 60, de 26 de maio 2020. Prefeitura Municipal de Imperatriz-MA. Leis e decretos municipais. 2020a. Disponível em: <http://novo.imperatriz.ma.gov.br/ media/site/download/legislacao/DECRETO_60_Codiv-19_-_de_26.05_-_flexibilizacao.pdf > . Acesso em: 10 jun. 2020.

IMPERATRIZ. Decreto ${ }^{\circ}$ 67, de 15 de junho de 2020. Prefeitura Municipal de Imperatriz-MA. Leis e decretos municipais. 2020b. Disponível em: <http://novo.imperatriz.ma.gov.br/media/site/download/ legislacao/DECRETO_67-Codiv-19_-_de_15.06_-_flexibiliza_1. pdf $>$. Acesso em: 29 jun. 2020.

IBGE - INSTITUTO BRASILEIRO DE GEOGRAFIA E ESTATÍSTICA. Educa IBGE - Conheça o Brasil - população cor ou raça. 2019. Disponível em: <https://educa.ibge.gov.br/jovens/conheca-o-brasil/populacao/18319-cor-ou-raca.html>. Acesso em: 11 jun. 2021.

IPHAN - INSTITUTO DO PATRIMÔNIO HISTÓRICO E ARTÍSTICO NACIONAL. Patrimônio Imaterial. s.d. Disponível em: <http:// portal.iphan.gov.br/pagina/detalhes/234>. Acesso em: 12 jun. 2020.

MAGNANI, José Guilherme Cantor. Festa no pedaço: cultura popular e lazer na cidade. 3 ed. São Paulo: Hucitec/Unesp, 2003.

MAGNANI, José Guilherme Cantor. Quando o campo é a cidade: fazendo antropologia na metrópole. In: Magnani, José Guilherme Cantor; Torres, Lilian de Lucca (org.). Na metrópole: textos de antropologia urbana. São Paulo: Edusp, 1996.

MARANHÃO. Governo do Estado do Maranhão. Secretária de Saúde do Maranhão. Boletim Epidemiológico covid-19 São Luís, 17 jun. 2020. Disponível em: <http://www.saude.ma.gov.br/wpcontent/ uploads/2020/06/BOLETIM-17-06.pdf>. Acesso em: 17 jun. 2020.

MONTANARI, MASSIMO. Comida como cultura. São Paulo: Editora Senac, 2008.

MENASCHE, Renata; ALVAREZ, Marcelo; COLLAÇO, Janine Helfst Leicht. Dimensões socioculturais da alimentação. Porto Alegre: UFRGS, 2012.

MELLO, Marco Antônio da Silva; SIMÕES, Soraya Silveira. Onde você mora? Propósitos e implicação do endereço. In: DUARTE, C. R; VILLANOVA, Roseline. Novos olhares sobre o lugar: ferramentas e 
metodologias, da arquitetura à antropologia. Rio de Janeiro: Contracapa, 2013.

PARK, Robert Ezra. A cidade: sugestões para a investigação do comportamento humano no meio urbano. In: VELHO, Otávio Guilherme (org.). O fenômeno urbano. Rio de Janeiro: Zahar, 1967.

PELLERANO, Joana A. Comendo coentro e açaí em São Paulo: pertencimento e diferença na alimentação de "outros brasileiros" na capital paulista. In: COLLAÇO, Janine Helfst Leicht; BARBOSA, Filipe Augusto Couto; ROIM, Talita Prado Barbosa (org.). Cidades e consumo alimentar: dinâmicas socioculturais do comer no espaço urbano. Goiânia: Imprensa Universitária, 2017. v. 1.

PEREIRA, Jesus Marmanillo. Cenários de medo e as sociabilidades pandêmicas no Maranhão. Revista Brasileira de Sociologia da Emoção. v. 19, n. 55, p. 67-86, maio 2020. Disponível em: <https://grem-grei. org/wpcontent/uploads/2020/05/5_JesusRBSEv19n55abril2020_Supl-Especial_maio2020.pdf>. Acesso em: 10 jun. 2020.

REIS, Hyana. Panelada e Imperatriz: de onde vem essa combinação? Correio popular, Imperatriz, edição 1030, ano VII. p. 06, 05 ago. 2018.

SEVERINO, Antônio Joaquim. Metodologia do trabalho científico. 24 ed. São Paulo: Cortez, 2016.

SILVA, Geane Oliveira; LOPES, Rita de Cássia Domingues. Comidas de rua: patrimônio, cultura e identidade local no norte do Tocantins. $O$ público e o privado, n. 32, p. 89-109, 2018. Disponível em: <http:// www.seer.uece.br/?journal=opublicoeoprivado\&page=article\&op=view\& path\%5B\%5D=2892>. Acesso em: 15 jun. 2020

SILVA, Luís Antônio Machado da. O significado do botequim. In: SILVA, Luís Antônio Machado da. Fazendo a cidade: trabalho, moradia e vida local entre as camadas populares urbanas. Rio de Janeiro: Mórula, 2016.

SOUSA. Jailson Macedo. A cidade na região e a região na cidade: a dinâmica socioeconômica de Imperatriz e suas implicações na Região Tocantina. Imperatriz: Ética, 2009.

SOUSA SANTOS, Boaventura de. A cruel pedagogia do vírus. São Paulo: Boitempo, 2020.

SOUSA, Emilene Leite De. Umbigos enterrados: corpo, pessoa e identidade Capuxu através da infância. Florianópolis: Editora da UFSC, 2017.

SOUZA, MILENA COSTA DE. Sociologia do consumo e indústria cultural. Curitiba: Intersaberes, 2017.

WOORTMANN, Ellen; CAVIGNAC, Julie A. Ensaios sobre a antropologia da alimentação: saberes, dinâmicas e patrimônios. Natal: EDUFRN, 2016. 